\title{
MARTHA DANTAS: o ensino da geometria na Bahia
}

\section{Martha Dantas: the teaching of geometry in Babia}

\author{
Maria Célia Leme da Silva ${ }^{a}$, Kátia Cristina Camargo ${ }^{b}$ \\ a Doutora em Educação pela PUC-SP, Assistente doutor da PUC-SP e UNIBAN-SP, \\ São Paulo, SP - Brasil, e-mail: mcelialeme@gmail.com \\ b Mestranda em Educação Matemática da PUC-SP, Santo André, SP - Brasil, e-mail: \\ camargo_kat@yahoo.com.br
}

\section{Resumo}

Este artigo faz parte de um projeto de pesquisa que pretende construir fatos históricos da educação matemática no Brasil, em especial, sobre o ensino de geometria na Bahia durante o Movimento da Matemática Moderna. Investigaremos, nesta pesquisa, que proposta de ensino da geometria esteve contida nos livros didáticos do curso ginasial do projeto: Processo entre a exposição e a descoberta - PROED, livros estes produzidos em Salvador na década de 70, que tinha como uma das autoras a matemática e educadora baiana Martha Maria de Souza Dantas. O projeto de pesquisa busca compreender como foi a introdução da geometria moderna na Bahia, para isso fizemos uma descrição e uma análise preliminar de documentos de dois projetos desenvolvidos em Salvador nas décadas de 60 e 70, entre eles o projeto ao qual deu origem aos livros didáticos que farão parte de nossa investigação. No corpo desse artigo apresentamos uma cronologia acadêmica de Martha Dantas, pois ao fazermos as primeiras leituras nos documentos recolhidos em Salvador, percebemos que os mesmos estavam fortemente atrelados à vida acadêmica dessa educadora.

Palavras-chave: Movimento da Matemática Moderna; Ensino de geometria; Martha Dantas.

Rev. Diálogo Educ., Curitiba, v. 8, n. 25, p. 701-714, set./dez. 2008 


\begin{abstract}
This article is part of project of research which intends to build up Historical facts of mathematics education in Brazil, in special, concerning teaching of geometry in Bahia, during the Movement of Modern Mathematics MMM. We investigated this research, which proposal of teaching of geometry was contained on books dedicated to elementary school in the project: "Process between exhibition and discovery "PROED. Those books, produced in Salvador in 70's decade, which one of the author the mathematics and educator from Bahia, Martha Maria de Souza Dantas. The project of research searchs to understand how was the introduction of modern geometry in Bahia, for this reason we prepared a preliminary description and analysis of original documents of two projects developed in Salvador during 60's and 70's decades between them the project which originated the didactic books, part of our investigation. On this article, we showed an academic analogy of Martha Dantas, because during our preliminary reading concerning documents from Salvador, we realized that those books were strongly harnessed to academic life of this educator.
\end{abstract}

Keywords: Modern Mathematics reform Movement; Geometry teaching; Martha Dantas.

\title{
INTRODUÇÃO
}

O presente artigo faz parte do projeto de pesquisa $O$ ensino da geometria na Babia em tempos do Movimento da Matemática Moderna e está ligado a um dos projetos do grupo de pesquisa de História da Educação Matemática - GHEMAT - A Matemática Moderna nas Escolas do Brasil e de Portugal: estudos históricos comparativos, subprojeto I A geometria moderna no ideário dos grupos de estudos brasileiros sobre o ensino de matemática, que tem por objetivo investigar como os Grupos de Estudo se apropriaram do ideário do MMM em relação ao ensino de geometria, identificando aspectos comuns que efetivamente foram incorporados às práticas pedagógicas.

O subprojeto A geometria moderna no ideário dos grupos de estudos brasileiros sobre o ensino de matemática focaliza, em especial, o ensino da geometria em três propostas defendidas pelo MMM: $1^{\text {a }}$ Geometria por meio dos estudos das

Rev. Diálogo Educ., Curitiba, v. 8, n. 25, p. 701-714, set./dez. 2008 
transformações geométricas; $2^{\mathrm{a}}$ Geometria pelo estudo dos espaços vetoriais; $3^{\mathrm{a}}$ Geometria a partir de modificações nos axiomas de Euclides. As investigações do projeto pretendem responder a questão: que geometria se consolidou no ensino brasileiro neste período?

Esta pesquisa tem como objetivo maior construir a história da educação matemática que, segundo Valente (2002) cabe a nós, historiadores da Educação Matemática, produzir os fatos históricos sobre o ensino da matemática, a partir de questionamentos que devem ser feitos nas marcas deixadas pelo passado. Poderemos escrever a história de práticas pedagógicas, com base na análise de documentos como: livros didáticos, arquivos escolares, arquivos pessoais de alunos e professores, legislações educacionais e depoimentos de protagonistas ainda vivos.

Estes documentos históricos se tornam fontes de pesquisa e passam a desempenhar um papel fundamental na construção dos fatos históricos, são eles que trarão respostas aos nossos questionamentos. Os documentos somente ganharão o "status" de fontes a partir das hipóteses e questões formuladas por nós historiadores, porém não basta encontrarmos os documentos, é preciso fazê-los "falarem”.

O desenvolvimento do artigo está dividido em duas partes: $A$ introdução da geometria moderna nos livros didáticos do Brasil e A cronologia acadêmica de Martha Maria de Souza Dantas, onde permeiam a criação do CECIBA (Centro de Ensino de Ciências da Bahia); o projeto PROED e os congressos internacionais nos quais Martha Dantas participou.

\section{A introdução da geometria moderna nos livros didáticos}

Um dos primeiros livros didáticos publicados no Brasil com conteúdos da Matemática Moderna foi escrito por Osvaldo Sangiorgi, líder e presidente do GEEM, ${ }^{1}$ uma coleção intitulada de Matemática Curso Moderno, editado pela Companhia Editora Nacional, a partir de 1963. Sobre a geometria, Leme da Silva (2006) diz que Sangiorgi traz nesta coleção a geometria euclidiana e a geometria dedutiva acrescida de novos postulados, que levam o aluno a fazer explorações. No apêndice ele apresenta a geometria pelas transformações geométricas.

\footnotetext{
Os estudos sobre Movimento da Matemática Moderna no Brasil indicam que esse movimento constituiu-se a partir de São Paulo, em 1961 com a criação do GEEM (Grupo de Estudos do Ensino da Matemática). O GEEM desenvolveu intensa atividade de divulgação da proposta da matemática moderna, organizou cursos em várias capitais do país, contribuindo assim para a divulgação da proposta em nível nacional. No final de 1963 o GEEM aparecia como responsável pelas mudanças no ensino de São Paulo, pelo fato de divulgar a matemática moderna e de reunir professores de todos os níveis de ensino de matemática e da capacidade de produzir novos materiais.
}

Rev. Diálogo Educ., Curitiba, v. 8, n. 25, p. 701-714, set./dez. 2008 
Segundo Leme da Silva (2006), Sangiorgi dá ênfase e considera como fundamental o estudo das transformações geométricas em sua argumentação teórica, mas não diz isso em seu livro didático. $\mathrm{O}$ autor não integra este estudo aos conceitos e propriedades geométricas, traz as transformações geométricas no final do livro e como apêndice, sem articulação ao corpo do livro.

"Identificamos muitas mudanças significativas no que diz respeito ao ensino de geometria no livro, e as transformações geométricas não estão entre elas" (LEME da SILVA, 2006, p. 22).

$\mathrm{Na}$ Bahia, a introdução de conteúdos da Matemática Moderna nos livros didáticos iniciou-se na Universidade Federal da Bahia com a criação, em 1965, do Centro de Estudos de Ciências da Bahia (CECIBA), cujo setor de matemática era coordenado pela professora Martha Maria de Souza Dantas, que usou em livros didáticos a proposta de ensino da geometria pelas transformações geométricas.

Utilizaremos como fontes os livros produzidos pelo grupo ao qual Martha fez parte, a primeira análise dará ênfase aos prefácios, sumários, as capas e as referências bibliográficas. Incluiremos também entrevistas, artigos e tese que encontramos na Universidade Federal da Bahia.

O historiador da Educação Matemática tem, como todo historiador, a tarefa de produzir fatos históricos. Sua especificidade é a de elaboração de fatos históricos relativos ao ensino de matemática.

Estudar as práticas da educação matemática de outros tempos, interrogar o que delas nos foi deixado, pode significar fazer perguntas para os livros didáticos de matemática utilizados em cotidianos passados. Eles - os livros didáticos - representam um dos traços que o passado nos deixou. Há uma infinidade de outros materiais que junto com os livros podem permitir compor um quadro da educação matemática de outros tempos (VALENTE, 2002, p. 12).

\section{Cronologia de Martha Maria de Souza Dantas}

Apresentamos aqui a vida acadêmica de uma das protagonistas da introdução da Matemática Moderna no ensino secundário da Bahia, suas viagens à Europa, sua participação em congressos internacionais, suas produções e seus projetos, para como já mencionado aqui, procurar elementos que influenciaram o grupo de Martha a usar em sua proposta o ensino da geometria pelas transformações geométricas.

Rev. Diálogo Educ., Curitiba, v. 8, n. 25, p. 701-714, set./dez. 2008 
Ao terminar o curso de magistério em 1942, Martha Dantas, iniciou sua carreira como professora primária. Ingressou na Faculdade de Filosofia da Universidade da Bahia, em 1945, onde fez o curso de Bacharelado e Licenciatura em Matemática, concluido em 1948. No dia seguinte de sua formatura foi convidada pelo Dr. Isaias Alves, diretor (na época) dessa mesma faculdade, para dirigir o Colégio de Aplicação que seria inaugurado em 1949.

"Peça importante na estrutura da Faculdade de Filosofia, o Colégio de Aplicação, nos termos da lei destinava-se à prática docente dos alunos matriculados no Curso de didática" (DANTAS, 1993, p. 12).

Em 1952, Martha foi convidada para lecionar Didática Especial da Matemática na Faculdade de Filosofia, em substituição ao professor Aristides da Silva Gomes. Contudo, Martha não se sentia apta para assumir o cargo, então a mesma conseguiu permissão da Faculdade para observar o ensino da matemática em países da Europa. Visitou a Bélgica, Inglaterra e a França, onde assistiu aulas em colégios e faculdades dos três países.

Na Bélgica, nas aulas de Metodologia Especial da Universidade Livre de Bruxelas, Martha verificou que a universidade orientava os futuros professores na preparação de aulas de Geometria com as demonstrações.

$\mathrm{Na}$ Inglaterra observou que os ingleses valorizavam o ensino da geometria, que inicialmente era bastante intuitivo, o método de ensino era o da redescoberta, o aprender fazendo.

Já na França o que mais lhe chamou a atenção foram os estágios realizados em Sèvres, onde participavam professores de todos os estados da França e de países estrangeiros. Esses estágios eram momentos de reflexão dos professores sobre as dificuldades, necessidades e conhecimentos dos alunos.

Quando volta da Europa, em 1953, deixou a Sub-direção do Colégio de Aplicação, mas decidiu, além de lecionar, ficar na Coordenação do Ensino de Matemática do mesmo. Martha tomou tal decisão, porque queria se dedicar mais ao ensino da matemática em nível médio e ao curso de Didática da Matemática em nível superior.

Em 1954, Martha publicou seu primeiro livro: Matemática para a primeira, segunda, terceira e quarta série ginasial, com Nilza da Rocha Santos e Helena Nogueira Bastos, pela Companhia Editora Nacional - SP.

Em 1955, com as idéias observadas em sua viagem à Europa, Martha promoveu o I Congresso Nacional de Ensino de Matemática no Curso Secundário, em Salvador, com o intuito de reunir professores de matemática de todo o país, para analisar a situação existente e traçar novos rumos para a Educação Matemática. Compareceram, neste congresso, representantes do Distrito Federal,

Rev. Diálogo Educ., Curitiba, v. 8, n. 25, p. 701-714, set./dez. 2008 
Rio Grande do Sul, Espírito Santo, Pernambuco, Rio Grande do Norte e de São Paulo, onde se destacou a presença de Omar Catunda: " "...] único professor de matemática do ensino superior, de fora da Bahia[...].”(DANTAS, 1993, p. 27).

Em 1958, obteve por meio do reitor da Faculdade de Filosofia da Bahia, uma bolsa de estudos do Instituto de Alta Cultura de Lisboa, Martha então vai a Portugal observar o ensino da matemática em nível secundário.

Em Portugal, ela aproveitou a oportunidade para fazer um estudo sobre Álgebra Linear na Faculdade de Ciências de Lisboa, com o professor Almeida Costa. Conheceu também nesta faculdade o professor e matemático Sebastião e Silva que tinha como preocupação a formação de professores de nível médio.

Sebastião utilizava manuais por ele escritos, nos cursos de atualização para professores de nível médio, com a intenção de prepará-los para assumirem a introdução da Matemática Moderna no ensino. Será que podemos dizer que foi em Portugal o primeiro contato de Martha com cursos e livros sobre a Matemática Moderna no ensino secundário?

\section{O CECIBA}

Em 1964 foram criados os Centros de Ensino de Ciências, por um convênio entre o MEC, Universidades e as Secretarias de Educação em alguns estados do Brasil.

$\mathrm{Na}$ Bahia, por meio desse convênio, foi criado em 1965 o CECIBA (Centro de Ensino de Ciência da Bahia), dirigido pelo professor José Walter Bautista Vidal. Martha ficou responsável pela coordenação do setor de Matemática e junto com Omar Catunda e suas colegas: Eliana Costa Nogueira, Eunice da Conceição Guimarães, Neide Clotilde de Pinho e Souza, Norma Coelho de Araújo, Maria Augusta Araújo Moreno, elaboraram o projeto: Desenvolvimento de um Currículo para o Ensino atualizado da Matemática, com o objetivo de introduzir a Matemática Moderna no ensino secundário. Produziram materiais didáticos, prepararam e deram cursos de aperfeiçoamento, estágios aos professores e o projeto foi levado para o Colégio de Aplicação da UFBa.

A criação do CECIBA foi de fundamental importância para a introdução da Matemática Moderna no ensino secundário:

\footnotetext{
Omar Catunda (1906-1986) foi professor da Faculdade de Filosofia, Ciências e Letras da Universidade de São Paulo (FFCLUSP). Ao aposentar-se, em 1962, parte para morar em Salvador, Bahia, e a partir de 1966, juntamente com um grupo de professoras, liderado por Martha Maria de Souza Dantas, elaboraram um projeto de livros de Matemática Elementar, cuja principal característica era uma reforma substancial no ensino da Geometria (LEME da SILVA, 2006).
}

Rev. Diálogo Educ., Curitiba, v. 8, n. 25, p. 701-714, set./dez. 2008 
Finalmente, procedeu-se a redação de textos que tornassem os programas elaborados exequíveis, permitindo introduzir no curso secundário os conceitos então recomendados. A redação dos novos textos foi viável porque contamos, para isso, com a colaboração de Omar Catunda que aceitou, inclusive, a proposta que lhe fizemos de usar, na abordagem da geometria, as transformações geométricas, recomendação centenária - feita por Felix Klein no século passado. (DANTAS, 1993, p. 23).

Os textos aos quais Martha se refere estão na biblioteca central da UFBA, contidos numa apostila datilografada datada de 1966 com as seguintes informações: Apostila de Matemática - $1^{a}$ série ginasial - curso experimental segundo os novos métodos do ensino da matemática. Publicada pela UFBA - Centro de Ensino de Ciências da Bahia (CECIBA), foi elaborada pelo grupo de Matemática do Departamento Estadual de Educação, constituído pelas professoras: Martha M. Dantas, Eliana Costa Nogueira, Maria Augusta Araújo Moreno e supervisão de Omar Catunda.

Na biblioteca central da UFBA encontramos exemplares dos livros Matemática Moderna I, II e III.

O volume I está sem data, escrito por Martha M. Dantas, Eliana Costa Nogueira, Maria Augusta Araújo Moreno, sob orientação de Omar Catunda e com colaboração na $1^{a}$ revisão de Norma Coelho de Araújo, Eunice da Conceição Guimarães e Neide Clotilde de Pinho e Souza, com os mesmos conteúdos da já mencionada Apostila de Matemática - $1^{a}$ série ginasial.

O volume II foi escrito em 1968 e o volume III e em 1969, por Martha, Eliana, Norma, Eunice e Neide sob orientação de Catunda. Nos conteúdos dos três volumes que foram publicados pelo CECIBA, constam à inserção da teoria dos conjuntos, das estruturas, lógica e geometria pelas transformações geométricas, ou seja, conteúdo proposto pelo Movimento da Matemática Moderna.

Em 1966, realizou-se o V Congresso Nacional Brasileiro de Ensino da Matemática, em São José dos Campos - SP, que foi coordenado pelo GEEM. Nesse congresso Martha conheceu pessoalmente George Papy. ${ }^{3}$ Ela já sabia do trabalho que ele realizava no Centro Belga de Pedagogia da Matemática, este trabalho era uma tentativa de introduzir a Matemática Moderna no ensino secundário.

George Papy, educador matemático belga. Direcionou seu trabalho para a melhoria da matemática escolar de modo a integrá-la àquela ensinada na universidade, desenvolvendo um programa rigoroso, com enfoque em Espaços Vetoriais e Geometria das Transformações (LEME da SILVA, 2006).

Rev. Diálogo Educ., Curitiba, v. 8, n. 25, p. 701-714, set./dez. 2008 
Martha, junto com Catunda, conversou com Papy sobre a possibilidade de enviarem os professores do CECIBA para estagiarem no Centro Belga, pois eles consideravam importante observar o estudo da geometria pelas transformações geométricas, que era realizado lá, e que coincidia com os realizados na Bahia, para a implantação do projeto Desenvolvimento de um Currículo para o Ensino atualizado da Matemática. Papy ofereceu duas bolsas de estudos e mais tarde, outras duas, então as quatro professoras Eliana, Eunice, Neide e Norma foram para a Bélgica, passaram um ano se preparando para introduzir a Matemática Moderna no ensino secundário da Bahia.

Com a ida das nossas já mencionadas companheiras de trabalho, na Bélgica conseguimos um modelo de projeto para a introdução da Matemática Moderna na escola secundária, depois de analisá-lo, fomos obrigadas a rejeitá-lo por ser demasiadamente abstrato. (DANTAS, 1993, p. 28).

Desenvolvemos um projeto menos audacioso que o da Bélgica, que foi testado no Colégio de Aplicação da UFBa. Posso garantir que não houve prejuízo para os alunos. E a experiência do Aplicação nos ajudou a encontrar o equilíbrio devido. A crítica dos professores que executavam a experiência, a reação dos alunos a ela submetidos e as recomendações dos Congressos internacionais que se realizavam, periodicamente, nos ajudaram na tarefa de avaliação do trabalho feito. (DANTAS, 1993, p. 28).

Em 1971, Martha defendeu a tese: Sobre a metodologia da Matemática, no Concurso para Professor Titular da área de Metodologia e Prática de Ensino da Matemática, realizada na Faculdade de Educação da UFBA. Nessa tese ela trata dos assuntos que se deve ensinar para alcançar os objetivos do ensino da matemática em nível secundário, também trata de como utilizar os conceitos que vão ser considerados e que já constam dos programas do Projeto: Desenvolvimento de um Currículo para o Ensino atualizado da Matemática, que era experimentado em Salvador.

Os assuntos tratados na tese foram: a linguagem dos conjuntos, as principais estruturas algébricas (anel, grupo e corpo) e as transformações geométricas.

Quando trata na tese das estruturas algébricas, Martha deixa bem claro que o ideal seria que o estudo das estruturas de grupo fosse iniciado a partir das transformações geométricas. Quando começa a tratar especificamente das transformações geométricas, ela apresenta as transformações como uma importante ferramenta no ensino da geometria. Em todo o seu trabalho refere-se às considerações e definições feitas por Felix Klein, defensor do estudo da geometria pelo conceito das transformações geométricas desde 1872.

Rev. Diálogo Educ., Curitiba, v. 8, n. 25, p. 701-714, set./dez. 2008 
Em sua tese consta nas referências bibliográficas o livro As transformações geométricas, de 1950, escrito em Lisboa por J. Sebastião Silva. Cabe aqui lembrar que em 1958, Martha conheceu o trabalho do professor Sebastião e Silva nos seus estudos em Portugal, possivelmente ela tenha adquirido esse livro nessa época, e pode ter sido um dos norteadores do Projeto: Desenvolvimento de um Currículo para o Ensino atualizado da Matemática, quando o grupo do CECIBA introduziu nos livros didáticos o ensino de geometria pelas transformações geométricas.

Nessa tese, Martha diz que nos livros Matemática Moderna III e Matemática Moderna IV existem muitos exemplos de utilização do conceito de transformações que permitem simplificar as demonstrações dos teoremas e propriedades de figuras.

Afirma também que as demonstrações do trabalho de geometria contidas nesses livros são graças a Catunda, que foi o idealizador da reformulação da matéria relativa ao ensino da geometria.

No final da tese Martha afirma ainda que, o projeto de atualização do ensino de matemática no curso secundário estava no sexto ano de experimentação no Colégio de Aplicação da UFBA e que já estava em fase de implantação em alguns Colégios Estaduais.

\section{O PROED}

Após o fim do CECIBA, em 1970, Martha e suas colaboradoras: Eliana, Norma, Eunice e Neide iniciaram um novo desafio, o Projeto para melhoria do ensino da Matemática de $5^{a}$ a $8^{a}$ série, onde contou com o apoio de Omar Catunda e Arlete Cerqueira Lima. ${ }^{4} \mathrm{O}$ projeto intitulou-se Processo entre a exposição e a descoberta - PROED e foram elaborados livros textos em forma de fichas:

A oportunidade que o CECIBA nos proporcionou de introduzir Matemática Moderna no curso secundário, de analisar os êxitos obtidos e as dificuldades criadas para o aluno pelo ensino adotado, para então buscar outros caminhos justificou, plenamente, a sua criação. Não fora a experiência do CECIBA, até hoje estaríamos sem saber por que rejeitar a Matemática Moderna e em que medida ela deveria ser rejeitada - definir o que devia ser excluído e o que era preciso conservar de tudo que foi feito. (DANTAS, 1993, p. 25-26).

4 Matemática e Professora aposentada do Instituto de matemática da UFBA Foi uma das fundadoras do Instituto de Matemática e Física. Também ajudou a divulgar e aplicar em alguns lugares o projeto "Processo entre a exposição e a descoberta".

Rev. Diálogo Educ., Curitiba, v. 8, n. 25, p. 701-714, set./dez. 2008 
Na Biblioteca da PUC-SP há uma coleção completa desses livros textos, doada pela professora Tânia M. Campos. Observamos nesta coleção que não foi publicada por uma editora, não existe ano de publicação, foi impressa pela Empresa Gráfica da Bahia e os autores são Martha, Eliana, Neide, Eunice e Catunda. Nas primeiras folhas da coleção, Martha e Arlete Cerqueira fazem agradecimentos a várias empresas, amigos e professores de alguns institutos da UFBA e da Universidade Estadual de Feira de Santana por terem feito doações para a re-edição da coleção. Em um desses livros existe uma data escrita á lápis, "1971", isso nos leva a supor que as primeiras edições dessa coleção saíram em 1971, ou seja, depois do fim do CECIBA e do início do novo projeto, mas ainda dentro do Movimento da Matemática Moderna.

Ao compararmos os livros de $7^{a}$ e $8^{a}$ séries do PROED com os livros Ensino Atualizado da Matemática 3 e 4 do antigo projeto Desenvolvimento de um Currículo para o Ensino atualizado da Matemática, percebemos que foi mantido o ensino da geometria por meio das transformações geométricas, porém a abordagem é completamente diferente. Os novos livros propõem um estudo dirigido com fichas de trabalho, nos quais o aluno interage com o conhecimento. Enquanto isso nos livros do antigo projeto o ensino de geometria pelas transformações geométricas era feito pela linguagem da teoria dos conjuntos, numa abordagem extremamente formal.

Pudemos examinar e observar na ficha 16, do livro de $7^{a}$ série, do PROED, que o estudo de geometria ali proposto começa com o aluno construindo segmentos orientados e translações desses segmentos, com malha quadriculada e régua. A partir dos segmentos orientados e translações o aluno é levado a construir os conceitos de simetria e assim são abordados conceitos e definições da geometria como: reta, semi-retas, retas paralelas, ângulos, etc. Isso nos leva a indagar: que fontes influenciaram o grupo nessa nova abordagem?

Na Biblioteca Central da UFBA, nas estantes onde se localizam os livros de matemática, não há nenhum exemplar dessa coleção, mas existem outros dois livros que nos despertaram interesse:

- Livro 1 - As transformaçoes geométricas e o ensino da geometria, editado em 1988 pelo Centro Editorial da UFBA (EUFBA), destinado aos professores. O livro é organizado em quatro capítulos: no primeiro os autores descrevem os problemas do ensino da geometria, no segundo e terceiro justificam os motivos do uso das transformações geométricas no ensino da geometria nas $7^{\mathrm{a}} \mathrm{e}$ $8^{\mathrm{a}}$ séries do $1^{\circ}$ grau e no quarto apresentam a distribuição da matéria por meio de fichas de trabalho;

Rev. Diálogo Educ., Curitiba, v. 8, n. 25, p. 701-714, set./dez. 2008 
- Livro 2 - As transformações geométricas e o ensino da geometria, vol. 1, editado em 1996 pela EUFBA, com as fichas de trabalhos direcionadas aos alunos da $7^{\mathrm{a}}$ série do $1^{\mathrm{o}}$ grau. O volume 2 foi encontrado em um sebo em Salvador, editado em 1998 pela EUFBA, com as fichas para a $8^{a}$ série.

Comparamos os três livros para verificar o tratamento e a abordagem dados ao ensino da geometria por meio das transformações geométricas. Constatamos que o tratamento e a abordagem são os mesmos dos livros de $7^{\mathrm{a}}$ e $8^{\mathrm{a}}$ séries do PROED.

Após dezessete anos do início do projeto nota-se que a Universidade interessa-se em editar somente a parte do livro que enfoca a geometria pelas transformações geométricas, o que nos leva a questionar as razões deste recorte.

Ao observar as referências bibliográficas do livro As transformacõos geométricas e o ensino da geometria, publicado em 1988, encontramos obras produzidas pelo grupo, entre elas um trabalho de Martha e Catunda sobre o ensino da geometria apresentado em mesa redonda na $5^{\text {a }}$ Conferência Interamericana, realizada em Campinas, São Paulo, de 13 a 15 de fevereiro de 1979. Entre as outras referências, com exceção de duas obras publicadas no Brasil, as demais são de origem estrangeira, publicadas entre os anos de 1959 a 1966. Tem-se nessas referências os anais dos congressos internacionais de 1973 e 1977. O que nos faz pensar que o grupo estava atualizado nas tendências internacionais do ensino da geometria por meio das transformações. No entanto isso nos leva a questionar: como eram tratadas as transformações geométricas nesses congressos?

Na entrevista de 1993, Martha diz que o PROED em fase experimental começou a ser aplicado em 1975, no Colégio Estadual Duque de Caxias por Eunice, Neide e Eliana. Disse também que no final dos anos 70 o projeto foi para a Escola Parque. Em 1988 o mesmo foi levado para Colégio Particular Soledade. Em 1990 para a Escola Reitor Miguel Calmon-Sesi-Fieb e para o Colégio Nossa Senhora da Piedade de Ilhéus (particular). E em 1992 foi levado para o Instituto Municipal de Educação pela professora Adelaide Reis Mendonça, da Faculdade de Educação da UFBa. Por meio desse relato observamos que durante os anos 80 e 90 o projeto continuou, ou seja, períodos em que o MMM já havia declinado.

\section{Os congressos internacionais}

Dos congressos internacionais de Educação Matemática dos quais Martha participou, destacamos aqui os trabalhos apresentados sobre transformações geométricas:

Rev. Diálogo Educ., Curitiba, v. 8, n. 25, p. 701-714, set./dez. 2008 
$1^{\circ}$ Congresso de Internacional de Educação Matemática, realizado em Lyon - França, de 24 a 30 de agosto de 1969. Um dos trabalhos apresentados nesse congresso foi o de Paul C. Rosenbloom, que Martha cita em uma de suas obras:

O mais simples sistema de postulados para o espaço euclidiano - a partir do qual define-se a geometria euclidiana - é, sem dúvida, a sua caracterização como vetorial munido de uma métrica: além da simplicidade mencionada, esta definição conduz a uma integração natural com a álgebra. O problema natural que sugere conexão com vetores é o da simetria nos ornamentos. (ROSENBLOOM apud DANTAS, 1989, p. 247).

$2^{\circ}$ Congresso Internacional de Educação Matemática, realizado em Exeter - Inglaterra, em 1972, onde ela apresentou um trabalho sobre Geometria das transformações. Um outro trabalho sobre transformações apresentado nesse congresso foi de Bruce Meserve que diz:

A amplamente publicada declaração "abaixo Euclides" deve ser aceita não como sinônimo de "abaixo a geometria", mas, sobretudo, como uma forte indicação de que a geometria deve ser ensinada como uma matéria viva e em crescimento, em vez de uma coleção de regras velhas. Nós estamos interessados, numa abordagem intuitiva e informal da geometria e, por isso, pensamos em transformações e vetores. Gostaríamos que os nossos estudantes fossem capazes de explorar relações entre figuras geométricas usando continuidade e simetria, e ainda que nossos estudantes fossem capazes de usar vetores e transformações que deixam invariantes os aspectos essenciais de um problema. (MESERVE apud DANTAS, 1989, p. 247).

$3^{\circ}$ Congresso Internacional de Educação Matemática, realizado em Kalsruhe - Alemanha, em agosto de 1976, Martha foi membro do painel que tratou do ensino da matemática no $2^{\circ}$ grau. Michael F. Atiyah no mesmo congresso defendeu as transformações, onde afirmou que: "o melhor aspecto da matemática moderna é a ênfase dada às idéias básicas, tais como simetria, continuidade e linearidade, que tem aplicações muito variadas. Isto deveria refletir-se no ensino, sempre que possível" (ATIYAH apud DANTAS, 1989, p. 247).

Rev. Diálogo Educ., Curitiba, v. 8, n. 25, p. 701-714, set./dez. 2008 
$6^{\circ}$ Congresso Internacional de Educação Matemática, realizado em Budapest - Hungria - 1988. Numa das sessões L. Grugnetti enfatizou o papel da geometria das transformações no ensino da geometria e a possibilidade de introduzir algumas provas euclidianas por meio de transformações geométricas.

Surge-nos o seguinte questionamento: em que medida esses trabalhos dos congressos influenciaram as produções do grupo no ensino da geometria pelas transformações geométricas?

\section{CONSIDERAÇÕES FINAIS}

Constatamos que Martha Dantas foi uma das protagonistas do Movimento da Matemática Moderna no Brasil. Sempre atualizada nas tendências da educação matemática internacional, lutava na Bahia por um ensino de matemática onde o aluno pudesse interagir na construção do conhecimento.

Mesmo após o esvaziamento do movimento Martha, junto com seu grupo, continuou na militância da educação matemática, formaram professores e aplicaram seus projetos nas escolas.

Pretendemos, a partir dos fatos e questionamentos que surgiram ao longo deste artigo, realizar entrevistas com pessoas que participaram dos projetos desenvolvidos na Bahia; analisar documentos dos congressos nacionais, interamericanos e internacionais aos quais estava presente o grupo de Martha, entre outros documentos que surgirem ao longo da pesquisa.

Também é nossa pretensão investigar de que forma a proposta do ensino de geometria pelas transformações foi concebida pelo ideário do MMM e de que forma influenciou o ensino de geometria na Bahia e no Brasil.

\section{REFERÊNCIAS}

CONGRESSO NACIONAL DE ENSINO DE MATEMÁTICA NO SECUNDÁRIO, 1., 1955, Salvador. Anais... Salvador: I CIBEM, 1957.

DANTAS, M. M. S; SANTOS, N. R.; BASTOS. H. N. Matemática: segunda série do curso ginasial. 3. ed. São Paulo: Brasil, 1954.

DANTAS, M. M. S. Sobre a metodologia da matemática. 1954. 38 f. Tese (Apresentada ao Concurso para Professor Titular da UFBA) Universidade Federal da Bahia, Salvador, 1971.

Rev. Diálogo Educ., Curitiba, v. 8, n. 25, p. 701-714, set./dez. 2008 
Uma experiência com o ensino da geometria através de transformações geométricas. Estudos do Instituto de Estudos e Pesquisas em Educação Anísio Teixeira, Rio de Janeiro, v. 2, n. 4, p. 246-253, 1989.

. Depoimento: uma mestra e sua vida. Cadernos do IFUFBA, Salvador, v. 6, n. 1, 2, p. 11-36, 1993.

DANTAS, M. M. et al. Curso experimental segundo os novos métodos do ensino da matemática. Apostilas de matemática I, Salvador: CECIBA, 1966.

Ensino atualizado da matemática: curso ginasial. 2. ed. São Paulo: EDART, 1971. v. 1-4.

. As transformações geométricas e o ensino da geometria. Salvador: UFBA, 1988.

LEME DA SILVA, M. C. O ensino da geometria no Brasil em tempos de Matemática Moderna: uma primeira análise nos livros didáticos de Sangiorgi. In: SEMINÁRIOS DE INVESTIGAÇÃO EM EDUCAÇÃO MATEMÁTICA, 17., 2006, Setúbal. Anais... Setúbal: Instituto Politécnico de Setúbal, 2006.

VALENTE, W. R. História da educação matemática: interrogações metodológicas. São Paulo: PUC-SP-GHEMAT, 2002. (mimeo).

Recebido: 04/06/2008

Received: 06/04/2008

Aprovado: 01/07/2008

Approved: 07/01/2008

Rev. Diálogo Educ., Curitiba, v. 8, n. 25, p. 701-714, set./dez. 2008 